\title{
Implementasi Web Portal Komunitas Gereja Menggunakan Metode Crowdsourcing Pada Gereja Santo Paulus Juanda
}

\author{
Valentinus Roby Hananto ${ }^{1}$, I Gusti Ngurah Alit Widana Putra ${ }^{2 *}$, Martinus Sony Erstiawan ${ }^{3}$ \\ 1,2,3Universitas Dinamika \\ e-mail: valentinus@dinamika.ac.id ${ }^{1}{ }^{2}$ alit@dinamika.ac.id ${ }^{2}{ }_{2}$ martinus@dinamika.ac.id $^{3}$ \\ *Penulis Korespondensi: E-mail: alit@dinamika.ac.id
}

\begin{abstract}
The Catholic Church of Santo Paulus Juanda currently has a population of around 2700 people that is spread in several sub-districts around the Juanda area, Sidoarjo regency. For the purposes of communication and publication of church activities, the church made a website. However, the lack of commitment from the management to manage website content resulted in a lack of information about church spiritual activities. Referring to these problems, one of the solutions offered is by building a web community church portal based on crowdsourcing, where the community can be actively involved in sharing information about church activities. The application is able to provide complete information on activities. People can access quickly through mobile phones or computers and connect to internet networks. To initiate this community involvement, journalism training was held for website contributors. With this training, people can be more active in filling in content that is in accordance with their respective characteristics and can overcome the lack of published information.
\end{abstract}

Keywords: Catholic Church, website, information portal, crowdsourcing, journalism

\begin{abstract}
Abstrak
Gereja Katolik Santo Paulus Juanda saat ini memiliki jumlah umat sekitar 2700 jiwa dan tersebar di beberapa kecamatan di sekitar wilayah Juanda, kabupaten Sidoarjo. Untuk keperluan komunikasi dan publikasi kegiatan gereja maka gereja membuat sebuah website. Akan tetapi, minimnya komitmen dari pengurus untuk megelola konten website mengakibatkan minimnya informasi mengenai kegiatan kerohanian gereja. Mengacu pada permasalahan tersebut, salah satu solusi yang ditawarkan yaitu dengan membangun web portal komunitas gereja berbasis crowdsourcing, di mana para umat dapat terlibat aktif dalam berbagi informasi mengenai kegiatan gereja. Aplikasi yang dibuat mampu memberikan informasi kegiatan secara lengkap, sehingga dapat mempermudah para umat dalam mengetahui semua informasi kegiatan gereja Umat dapat mengakses dengan cepat melalui handphone atau komputer dan terhubung dengan jaringan internet. Untuk menginisiasi keterlibatan umat ini, maka diadakan pelatihan jurnalistik bagi kontributor website. Dengan adanya pelatihan ini, umat dapat lebih aktif mengisi konten yang sesuai dengan karakteristik mereka masing - masing serta dapat mengatasi kurangnya informasi yang dipubilkasikan.
\end{abstract}

Kata kunci: Gereja Katolik, website, portal informasi, crowdsourcing, jurnalistik

\section{PENDAHULUAN}

Gereja Katolik Santo Paulus Juanda memiliki alamat di Jl. Raya Juanda Km 1,2 Sidoarjo. Bangunan gereja berdiri di atas lahan seluas $400 \mathrm{~m}^{2}$ dan mulai dibangun pada tanggal 27 April 2003. Gereja ini diberkati oleh Duta Besar Vatikan, Bapak Uskup Agung Malcolm A. Ranjith, pada tanggal 20 Agustus 2005 dan kemudian diresmikan pertama kali pada tanggal 1 Mei 2008. Gereja yang berulang tahun setiap tanggal 1 Mei ini juga memiliki fasilitas Oratorium yang berada di sisi timur gedung gereja. Oratorium yang diberi nama "Bunda Maria Selalu 
Menolong" ini diberkati tepat pada Hari Raya Santa Maria Bunda Allah yang jatuh pada tanggal 1 Januari 2016, oleh RD. Yuventius Fusi Nusantoro dari Vikep Surabaya Selatan. Jumlah umat pada Gereja Santo Paulus sudah mencapai 2700 jiwa. Tampak depan dari gereja Santo Paulus dapat dilihat pada gambar 1.



Gambar 1. Tampak depan Gereja Katolik Santo Paulus Juanda

Gereja Katolik Santo Paulus Juanda memiliki jumlah umat yang sangat banyak dan tersebar di beberapa kecamatan di sekitar wilayah Juanda, kabupaten Sidoarjo. Seperti umumnya suatu organisasi pasti memiliki banyak kegiatan yang telah diadakan oleh anggota, demikian pula Gereja Santo Paulus. Kegiatan yang dilakukan oleh gereja Santo Paulus umumnya terdiri atas kegiatan misa harian, misa hari raya, serta kegiatan rohani lainnya. Kegiatan-kegiatan ini dapat dipublikasikan melalui media website yang sudah pernah dibuat oleh Gereja Santo Paulus. Namun karena keterbatan dari anggota kelompok sosial gereja untuk mengupdate konten berita, website tersebut minim informasi mengenai kegiatan kerohanian gereja. Hal ini tentu tidak efektif, karena umat tidak dapat mengakses infomasi yang dibutuhkan pada website gereja.

Mengacu pada permasalahan tersebut, salah satu solusi yang ditawarkan yaitu dengan membangun web portal komunitas gereja berbasis crowdsourcing, di mana para umat dapat terlibat aktif dalam berbagi informasi mengenai kegiatan gereja yang akan maupun sudah terlaksana. Aplikasi tersebut diharapkan mampu memberikan informasi kegiatan secara lengkap, sehingga dapat mempermudah para umat dalam mengetahui semua informasi kegiatan gereja melalui aplikasi ini. Umat dapat mengakses dengan cepat melalui handphone atau komputer dan terhubung dengan jaringan internet tanpa dibatasi tempat, ruang dan waktu. Agar web portal ini dapat dimanfaatkan dengan baik, akan diadakan pelatihan jurnalistik bagi umat yang ditunjuk menjadi kontributor website.

Secara umum prioritas dalam kegiatan pengabdian masyarakat ini adalah mengedukasi pengurus gereja akan pentingnya portal informasi gereja ini. Hal ini merupakan permasalahan penting untuk menjawab kebutuhan umat terkait informasi gereja. Kemampuan portal yang lebih spesifik adalah penyediaan kandungan informasi yang dapat diakses menggunakan berbagai perangkat seperti komputer, notebook, maupun smartphone. 


\section{METODE PELAKSANAAN}

Tahapan/langkah-langkah untuk mencari solusi dari permasalahan pada Gereja Santo Paulus Juanda dalam upaya pembuatan web portal komunitas gereja, secara detail diuraikan dalam prosedur kerja yang mendukung realisasi pembuatan aplikasi. Prosedur kerja dapat dilihat di Gambar 2.



Gambar 2. Prosedur kerja

Menurut Pressman (2015), System Development Life Cycle (SDLC) atau Siklus Hidup Pengembangan Sistem adalah proses perancangan sistem serta metodologi yang digunakan untuk mengembangkan sistem-sistem tersebut. SDLC yang digunakan adalah model Waterfall. Sebelum perancangan sistem, diskusi dengan mitra dilakukan untuk mengetahui kebutuhan sistem yang dibutuhkan.

Mia Meilani (2015) menulis tentang Crowdsourcing diartikan secara kata perkata mempunyai terjemahan bebas yakni: Crowd yang berarti kerumunan orang, Sourcing yang berarti sumberdaya. Apabila digabungkan akan berarti sebagai sesuatu system atau konsep yang sumber daya berbasis kerumunan. Definisi sederhana crowdsourcing adalah suatu aktifitas atau tindakan yang dilakukan oleh suatu perusahaan atau institusi yang mengambil salah satu fungsi pekerjaan tugas yang seharusnya dilakukan oleh karyawannya 
disebarluaskan secara terbuka dan bebas untuk orang banyak/kerumunan yang terkoneksi dengan jaringan komputer, dalam hal ini internet. Aksi tersebut akan berubah menjadi bentuk produksi sekawan (peer production) manakala suatu sudah terjadi kesepakatan kerja.

Setelah web aplikasi portal informasi gereja sudah siap diemplementasikan, tahapan berikutnya adalah memberikan sosialisasi dan pelatihan bagi mitra. Sosialisasi tentang web portal komunitas gereja diadakan untuk optimalisasi penyebaran informasi profil gereja dan kegiatan gereja. Selain itu, pelatihan untuk mendukung pengelolaan web portal komunitas gereja juga dilakukan dengan mengadakan pelatihan jurnalistik.

\section{HASIL dan PEMBAHASAN}

\section{Survey ke lokasi mitra untuk mengetahui kebutuhan}

Survey awal ke lokasi mitra dilakukan pada tanggal 2 dan 5 Agustus 2018. Wawancara dilakukan dengan Romo Kristoforus selaku Romo Paroki Gereja Santo Paulus Juanda. Dari hasil wawancara, diketahui bahwa Paroki memiliki suatu website yang dulunya digunakan untuk media komunikasi gereja dengan umat. Akan tetapi, website yang telah dimiliki oleh Gereja Santo Paulus telah dilepas pertanggungjawaban oleh kelompok sosial gereja karena kesibukan yang mereka miliki. Hal tersebut dapat mengakibatkan minimnya informasi mengenai kegiatan kerohanian gereja yang akan membuat para umat mendatangi langsung ke gereja bagian sekretariat karena keinginannya untuk mendapatkan informasi kegiatan gereja yang lebih rinci.

Solusi yang ditawarkan oleh tim adalah Web Portal Komunitas Gereja Santo Paulus menggunakan metode Crowdsourcing sebagai solusi untuk memberikan informasi yang dibutuhkan oleh para umat tersebut. Aplikasi tersebut telah mengintegrasikan informasi kegiatan - kegiatan gereja menjadi satu kesatuan dengan media berbasis web. Dengan menggunakan metode Crowdsourcing, salah satu fungsi pekerjaan meperbarui konten berita website yang seharusnya dilakukan oleh kelompok sosial gereja dapat dialihkan untuk disebarluaskan secara terbuka dan bebas untuk umat yang terkoneksi dengan jaringan komputer melalui internet.

\section{Diskusi dengan mitra untuk mencari solusi}

Diskusi terkait solusi aplikasi yang akan dibuat dilakukan pada tanggal 26 Agustus 2018 di Gereja Santo Paulus Juanda. Diskusi dilakukan bersama dengan Romo Paroki Gereja Santo Paulus Juanda, yaitu Romo Kristoforus. Mengawali pertemuan ketua tim memaparkan tujuan pertemuan kepada mitra, dan dilanjutkan dengan mendemonstrasikan rancangan web portal komunitas Gereja dihadapan Romo sambil menjelaskan alur kerja web portal komunitas tersebut.

Setelah selesai melakukan presentasi, tim melakukan diskusi dengan mitrauntuk mencari masukan sebelum nantinya web portal tersebut dibuat, adapun masukkan yang didapatkan sebagai berikut:

a) Perlu adanya fitur untuk cara mendapatkan kembali password/login jika lupa.

b) Perlu ada master/ketua admin untuk mengelola akun kategori admin.

c) Akun dibagi kedalam 3 jenis yaitu: Admin, Kontributor dan User.

d) Admin memiliki akses untuk menghapus artikel yang sudah diterbitkan atas dasar masukkan dari contributor dan/atau user.

e) Kontributor memiliki hak akses menulis dan menerbitkan artikel juga sebagai verifikator terhadap artikel yang dikirim oleh user. Selain itu dapat menulis komentar dalam artikel. 
f) User memiliki hak akses menulis komentar dan mengirim draft artikel yang ingin diterbitkan.

g) Artikel yang sudah diterbitkan dapat dibaca oleh semua orang tanpa perlu mendaftar.

h) Selain berbasis web, akan lebih bagus jika ada aplikasi mobilenya atau paling tidak shortcut untuk smartphone Android.

i) Domain yang nantinya akan digunakan adalah .org

j) Kontributor memiliki hak untuk menyetujui dan menolak suatu komentar dari user sebelum diterbitkan pada suatu artikel.

k) Tidak diperlukan warna untuk kategori artikel.

l) Pengurus yang akan ditampilkan dalam web adalah pengurus web saja bukan pengurus gereja.

m) Kontributor juga memiliki akses ke berita.

\section{Merancang aplikasi portal informasi}

Perancangan sistem dilakukan dengan membuat perancangan sistem yang akan dibuat. Desain yang dibuat tidak hanya berupa tampilan dari aplikasi saja tetapi meliputi keseluruhan desain yang telah disesuaikan dengan analisis sistem pada tahapan awal. Rancangan sistem berawal dari membuat diagram Input-Proses-Output (IPO) di mana sebuah inputan dibutuhkan untuk tahap proses tertentu yang menghasilkan sebuah output. Berikut diagram IPO pada gambar 3 .

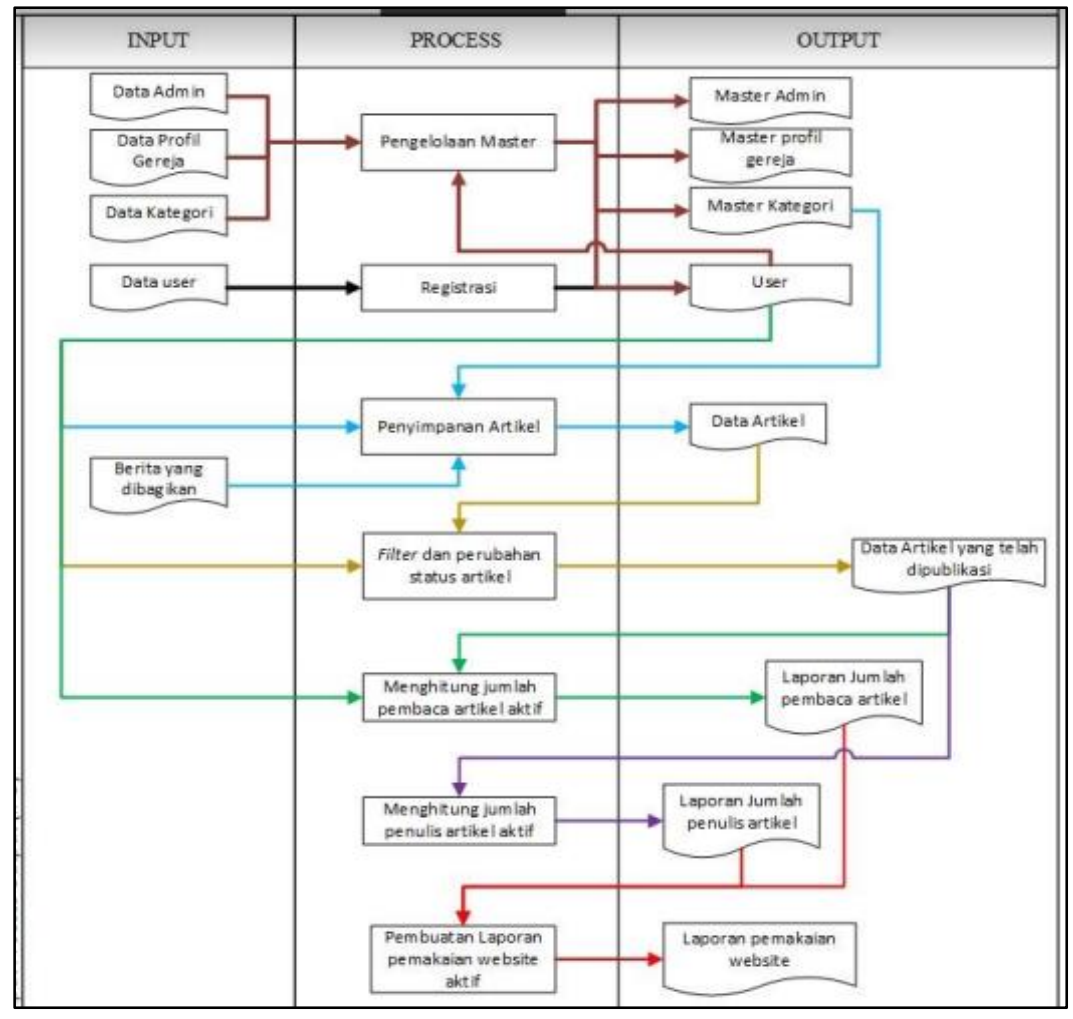

Gambar 3. Prosedur kerja 


\section{Implementasi dan Evaluasi Sistem}

Setelah web selesai dibuat dan siap untuk diuji coba, langkah selanjutnya adalah mendaftarkan web tersebut ke layanan hosting web dengan nama domain yang sudah ditentukan. Berdasarkan kesepakatan dengan Romo Paroki, nama domain yang digunakan adalah www.santopaulusjuanda.org. Layanan hosting yang digunakan memiliki durasi selama satu tahun, selanjutnya perlu diperpanjang lagi setelah satu tahun pertama.

Pembuatan web portal komunikasi ini tidak bisa optimal apabila tidak didukung oleh kontributor web yaitu umat paroki. Umat paroki diharapkan untuk aktif berkontribusi dalam mengisi konten website sebagai media bertukar informasi seputar kegiatan di Paroki Santo Paulus Juanda. Untuk menginisiasi keterlibatan umat ini, maka kami bersama Romo Paroki sepakat untuk mengadakan pelatihan jurnalistik bagi kontributor website. Sebagai persiapan pelatihan ini, tim melakukan koordinasi dengan Romo Paroksi dan seksi komsos yang ada di Paroki Santo Paulus Juanda.

\section{Pelatihan jurnalistik untuk kontributor website}

Pelatihan jurnalistik dilakukan pada hari Minggu tanggal 11 November 2018 mulai pukul 10.00 sampai pukul 12.30. Pelatihan ini diikuti 50 peserta yang merupakan perwakilan umat dari setiap lingkungan di Paroki Santo Paulus Juanda. Materi jurnalistik disampaikan oleh Petrus Riski Lesetiya Mulya Srilambang, S.Sos., M.I.Kom. yang sudah memiliki banyak pengalaman sebagai reporter dan jurnalis khususnya di lingkup gereja. Kegiatan ini diawali dengan sambutan dari Romo Paroki (RD Tri Kuncoro Yekti) yang sekaligus memberikan motivasi dan arahan terkait upaya gereja untuk melibatkan umat dalam meningkatkan literasi media (gambar 4).

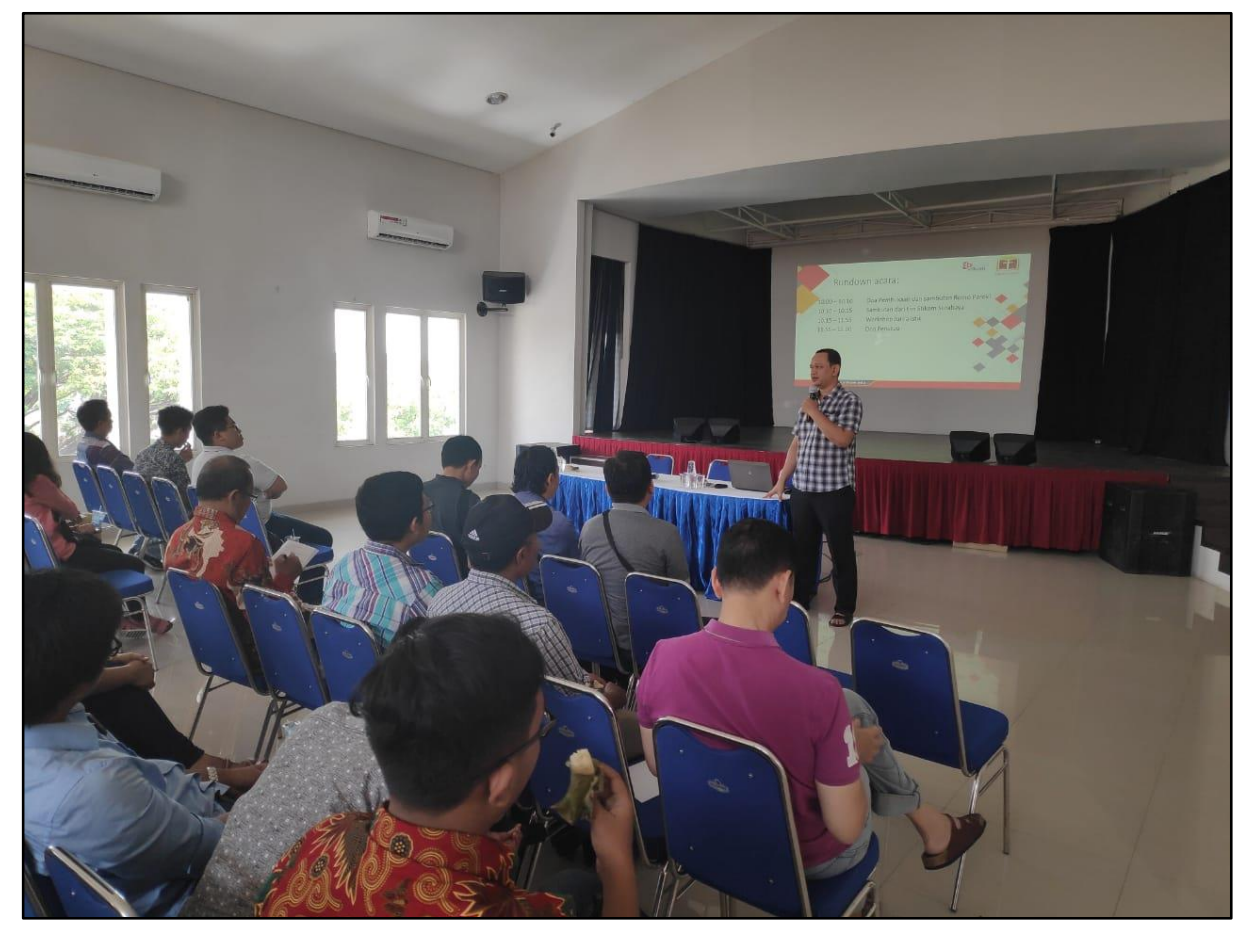

Gambar 4. Acara pelatihan 
Selanjutnya acara dilanjutkan dengan sesi materi jurnalistik oleh pemateri. Materi yang disampaikan meliputin dasar-dasar penulisan berita secara singkat, padat, dan jelas serta kode etik dalam jurnalistik. Acara berlangsung dengan baik dan peserta juga turut aktif bertanya tentang materi yang disampaikan. Pada satu jam terakhir, peserta diminta membuat berita singkat yang kemudian akan dievaluasi kekurangannya oleh pemateri. Contoh hasil berita yang ditulis oleh umat dan revisi dari pemateri dapat dilihat pada tabel 1.

Tabel 1. Hasil konten berita

\begin{tabular}{ll} 
No & \multicolumn{2}{c}{ Isi berita } \\
\hline 1 & $\begin{array}{l}\text { Kegiatan BIAK diadakan setiap hari } \\
\text { Sabtu pada pukul } 4 \text { s.d } 6 \text { sore di Ruko } \\
\text { Delta Fortuna nomor 18. Kegiatan ini }\end{array}$ \\
& diadakan agar hubungan antara \\
& anak-anak di wilayah FA bisa \\
& semakin erat dan mereka bisa \\
mengenal satu sama lain. Disana \\
anak-anak akan diajak bermain, \\
bernyanyi bersama, mewarnai, dan \\
banyak kegiatan seru lainnya.
\end{tabular}

2 Donor darah paroki ST paulus juanda pada tanggal 21 oktober 2018 pukul 10.00 WIB - 12.00 WIB yang bertempat di halaman belakang gereja diadakan untuk membantu PMI untuk menggalang sumbangan kantong darah untuk rumah sakit yang membutuhkan acara tersebut di buka untuk umum dan warga paroki ST paulus Juanda.

3 Berbekal keinginan berkeluarga cemara. Lingkungan Simon 2 Juanda mengadakan retret keluarga. Kegiatan tersebut diadakan sabtu minggu, Batu Malang. Bruder Yohanes sebagai narasumber utama membawakan materi dengan kocak. Peserta tak merasa belajar. Semua materi disajikan dengan obrolan santai. Retret ditutup dengan misa. Semoga rasa kebersamaan ini tak cepat berakhir.

4 Zaman media sosial yang makin berkembang maka umat dan kepala paroki santo paulus juanda, ingin menggunakan media sosial ini dgn

Hari Minggu, 11 November 2018, Paroki St. Paulus Juanda menggelar Pelatihan Jurnalistik untuk umat paroki, sebagai bekal dalam bermedia sosial di era kemajuan teknologi. 


\begin{tabular}{ll}
\hline No Isi berita & \multicolumn{1}{c}{ Revisi } \\
\hline efektif dan dapat berperan sebagai & Melalui pelatihan ini, Kepala Paroki St. Paulus \\
sumber informasi dan komunikasi & Juanda ingin mengajak umat berperan serta \\
antar umat. Maka hari ini tgl 12 nop & aktif, menggunakan media untuk \\
2018. Paroki berinisiatif utk & menggunakan media sosial secara efektif dan \\
memberikan pelatihan jurnalistik & bertanggung jawab. \\
dgn menghadirkan teman teman dari & \\
Stikom Surabaya. & \\
\hline
\end{tabular}

\section{KESIMPULAN}

Berdasarkan hasil uji coba dan evaluasi yang telah dilakukan terhadap Aplikasi Portal Komunitas Gereja Katolik Santo Paulus Berbasis Web menggunakan metode Crowdsourcing, maka dapat ditarik kesimpulan bahwa aplikasi yang telah dibuat dapat mengintegrasikan informasi kegiatan - kegiatan gereja menjadi satu kesatuan dengan media berbasis web. Dengan menggunakan metode Crowdsourcing, fungsi pekerjaan tugas mengupdate konten berita website telah dialihkan untuk disebarluaskan secara terbuka dan bebas untuk umat yang terkoneksi dengan jaringan komputer melalui internet. Para umat dapat terlibat aktif dalam berbagi informasi mengenai kegiatan gereja yang akan maupun sudah terlaksana. Dengan adanya sosialisasi dan pelatihan jurnalistik, umat dapat lebih aktif mengisi konten yang sesuai dengan karakteristik mereka masing - masing serta dapat mengatasi kurangnya informasi yang dipubilkasikan.

\section{UCAPAN TERIMAKASIH}

Penulis mengucapkan terima kasih kepada Romo Tri Kuncoro Yekti selaku mitra dan Bapak Petrus Riski Lesetiya Mulya Srilambang selaku pemateri yang telah memberi dukungan terhadap pengabdian ini.

\section{DAFTAR PUSTAKA}

Meilani, Mia, dkk. (2015). Pembangunan Portal Web Crowdsourcing Event Perguruan Tinggi menggunakan Metode Iterative Incremental (Modul Penyelenggara Event). e-Proceeding of Engineering, 2(2), 5703.

Pressman, R. (2015). Rekayasa Perangkat Lunak: Pendekatan Praktisi Buku 1. 